\title{
Tumor cell invasion of model 3-dimensional matrices: demonstration of migratory pathways, collagen disruption, and intercellular cooperation
}

\author{
KEI HORINO,$*{ }^{\dagger}$ ANDREI L. KINDEZELSKII, $*$ VICTOR M. ELNER, ${ }^{\dagger}$ BRET A. HUGHES, ${ }^{\dagger}$ \\ AND HOWARD R. PETTY*,1 \\ *Department of Biological Sciences, Wayne State University, Detroit, Michigan 48202, USA; and \\ ${ }^{\dagger}$ Department of Ophthalmology, University of Michigan, Ann Arbor, Michigan, USA
}

ABSTRACT We report a novel 3-dimensional model for visualizing tumor cell migration across a nylon mesh-supported gelatin matrix. To visualize migration across these model barriers, cell proteolytic activity of the pericellular matrix was detected using Bodipy-BSA (fluorescent upon proteolysis) and $\mathrm{DQ}^{\mathrm{TM}}$ collagen (fluorescent upon collagenase activity). For 3-dimensional image reconstruction, multiple optical images at sequential $z$ axis positions were deconvoluted by computer analysis. Specificity was indicated using wellknown inhibitors. Using these fluorescent proteolysis markers and imaging methods, we have directly demonstrated proteolytic and collagenolytic activity during tumor cell invasion. Moreover, it is possible to visualize migratory pathways followed by tumor cells during matrix invasion. Using cells of differing invasive potentials (uPAR-negative T-47D wild-type and uPAR-positive T-47D A2-1 cells), we show that the presence of the T-47D-A2-1 cells facilitates the entry of $T-47 D$ wild-type cells into the matrix. In some cases, wild-type cells follow T-47D A2-1 cells into the matrix whereas other T-47D-wild-type cells appear to enter without the direct intervention of T-47D A2-1 cells. Thus, we have developed a new 3-dimensional model of tumor cell invasion, demonstrated protein and collagen disruption, mapped the pathways followed by tumor cells during migration through an extracellular matrix, and illustrated cross-talk among tumor cell populations during invasion.-Horino, K., Kindezelskii, A. L., Elner, V. M., Hughes, B. A., Petty, H. R. Tumor cell invasion of model 3-dimensional matrices: demonstration of migratory pathways, collagen disruption, and intercellular cooperation. FASEB J. 15, 932-939 (2001)

Key Words: transmigration $\cdot$ metalloproteinase $\cdot H T 1080$ cells $\cdot T-47 D$ cells $\cdot$ gelatin-nylon mesh matrix

Tumor CELL INVASIVENESS is a cardinal feature distinguishing malignant from benign disease. Malignant tumor cells penetrate basement membranes, connective tissues, and cellular planes (1). Invasiveness requires several distinct cellular functions involved in tumor cell motility, including adhesion, detachment, and pericellular proteolysis. Metastatic cells display increased production of proteolytic enzymes including lysosomal hydrolyses, collagenases, and plasminogen activator (2). The expression of certain cell surface protease receptors is also increased on metastatic cells (3). Thus, the nature of matrix proteolysis during tumor cell migration is central to understanding the invasive cell phenotype (4-8).

A variety of methods have been developed to explore tumor cell invasiveness (9). In vitro assays of tumor cell invasiveness include penetration of the urinary bladder wall $(10,11)$, human amnion $(12,13)$, chorioallantoic membrane $(11,14)$, blood vessels $(11)$, and lens capsule (15). Reconstituted basement membrane components have also been used to assay invasive properties of tumor cells. Such assays typically involve a layer of Matrigel atop a porous filter, which is then placed in a Boyden chamber. The invasive potential of tumor cells placed in the Boyden chamber can be quantitated by counting tumor cells across the filter (16). However, these techniques do not allow for direct optical microscopy of a sample nor do they allow for the detection of biochemical reactions occurring during invasion. We developed a novel 3-dimensional model based on a supported gelatin layer that more closely resembles the physiological environment and permits visualization of cell migration pathways and biochemical reactions via optical microscopy.

\section{MATERIALS AND METHODS}

Cell culture

The human fibrosarcoma cell line HT1080 was obtained from American Type Culture Collection (Bethesda, Md.). HT1080 cells were grown at $37^{\circ} \mathrm{C}$ in DMEM (Life Technology, Inc., Grand Island, N.Y.) supplemented with $10 \%$ FBS (Summit Biotechnology, Fort Collins, Colo.) and 1\% PSA (penicillin G/streptomycin/amphotericin B) (Life Technology). Cells were grown in sterile flasks and passaged using trypsin-EDTA (Life Technology), as described previously (17).

\footnotetext{
${ }^{1}$ Correspondence: Department of Biological Sciences, Wayne State University, Detroit, MI 48202, USA. E-mail: hpetty@biology.biosci.wayne.edu
} 
The T-47D and T47 A2-1 cell lines were the generous gifts of Dr. Robert Todd (Division of Hematology and Oncology, University of Michigan School of Medicine, Ann Arbor, Mich.). They were grown at $37^{\circ} \mathrm{C}$ in RPMI1640 (Life Technology) supplemented with 10\% FBS (Summit), 1\% PSA (Life Technology), and $0.2 \mathrm{IU} / \mathrm{ml}$ bovine insulin (Sigma Chemical Co, St. Louis, Mo.). Cells were passaged as described above.

\section{DiI labeling}

Labeling tumor cells by DiI (1,1'-dioctadecyl-3,3,3',3'-tetramethylindocarbocyanine; Molecular Probes, Eugene, Oreg.) was performed according to the method of Kuriyama et al. (18) with minor modifications. In brief, DiI was prepared as a $2.0 \mathrm{mg} / \mathrm{ml}$ solution in DMSO. The DiI solution was routinely sonicated before application to cells. Cells were detached by treatment with trypsin-EDTA, suspended with Hank's balanced salt solution (HBSS) at a concentration of $5 \times 10^{5}$ cells $/ \mathrm{ml}$, and stained by incubating with DiI (final concentration is $20 \mu \mathrm{g} / \mathrm{ml}$ ) for $1 \mathrm{~h}$ at $37^{\circ} \mathrm{C}$ with gentle agitation at 15 min intervals. After staining, the cells were washed twice by centrifugation and seeded onto the surfaces of the gelatinnylon mesh.

\section{Nylon membrane preparation}

Nylon mesh ( $125 \mu \mathrm{m}$ pores, $80 \%$ open) cut in $12 \mathrm{~mm}$ squares was rinsed in $75 \%$ ethanol for $5 \mathrm{~min}$. A $6 \%$ to $10 \%$ gelatin solution was prepared by boiling gelatin in HBSS. To avoid denaturation of the $\mathrm{DQ}^{\mathrm{TM}}$ collagen, the solution was allowed to cool to $\sim 42^{\circ} \mathrm{C}$ before the addition of this compound. Ten microliters of cell attachment factor (Cell Systems Corporation, Kirkland, Wash.) was placed on a coverslip for $15 \mathrm{~min}$ at $42^{\circ} \mathrm{C}$ in an incubator. After drying, a sterile nylon mesh was placed on the coverslip. Fifty microliters of 6 to $10 \%$ gelatin solution containing $10 \%$ fetal bovine serum (FBS) and Bodipy-BSA (at a final concentration of $1 \mathrm{mg} / \mathrm{ml}$ ) or $\mathrm{DQ}^{\mathrm{TM}}$ collagen (at a final concentration of $1 \mathrm{mg} / \mathrm{ml}$ ) were placed on the nylon mesh and allowed to harden in a refrigerator at $4^{\circ} \mathrm{C}$ for $10 \mathrm{~min}$. The gelatin-nylon mesh matrix on the coverslip was then placed at room temperature.

\section{Transmigration of tumor cells}

HT1080 cells were detached from culture flasks by treatment with trypsin-EDTA. After detachment, the HT1080 cells were resuspended in culture medium supplemented with $10 \%$ FBS for $10 \mathrm{~min}$ at room temperature to inactivate any remaining trypsin activity. After centrifugation at $1000 \mathrm{rpm}$ for $5 \mathrm{~min}$, HT1080 cells were seeded onto the surfaces of the gelatinnylon mesh matrices in $50 \mu \mathrm{l}$ of $6 \%$ gelatin solution containing $10 \%$ FBS. They were then incubated for 2 to $4 \mathrm{~h}$ at $37^{\circ} \mathrm{C}$ in a $5 \% \mathrm{CO}_{2}$ incubator. The gelatin-nylon mesh matrices and coverslips were then mounted on glass slides for microscopic observation.

\section{Inhibition of the collagenase activity}

To inhibit metalloproteinase activity, 1,10 phenanthroline (Eluka Chemical Corp., Ronkonkoma, N.Y.) was used (19). During preparation of the gel-nylon mesh matrix, 1,10 phenanthroline was incorporated into the matrix at a final concentration of $10 \mathrm{mM}$. Control gels contained only ethanol, the solvent used for 1,10 phenanthroline. HT1080 cells were seeded and incubated as described above. After $2 \mathrm{~h}$ of incubation at $37^{\circ} \mathrm{C}$, we counted the number of cells with associated pericellular fluorescence in four high-power microscopic fields.

\section{Inhibition of urokinase-type plasminogen activator}

To inhibit urokinase-type plasminogen activator, PAI-I (plasminogen activator inhibitor I; American Diagnostica Corporation, Joplin, Mo.) was used. During preparation of the gel-nylon mesh matrix, PAI-I was incorporated into the matrix at a final concentration of $0.05 \mathrm{mg} / \mathrm{ml}$. Control gels contained only HBSS, the solvent used for PAI-I. HT1080 cells were seeded and incubated as described above. After $2 \mathrm{~h}$ of incubation at $37^{\circ} \mathrm{C}$, we counted the number of cells with pericellular fluorescence in four high-power microscopic fields.

\section{Fluorescence Microscopy and Image Reconstruction}

To visualize proteolytic activity, Bodipy-BSA (4,4-difluoro-5,7dimethyl-4-bora-3a,4a diaza-5-indacene-3-propionic acid-conjugated BSA; Molecular Probes) and $\mathrm{DQ}^{\mathrm{TM}}$ collagen (type IV from human placenta, fluorescein conjugate; Molecular Probes cat. no. D-12052) were used. Bodipy-BSA becomes fluorescent upon exposure to several proteases, especially urokinase-type plasminogen activator (20). $\mathrm{DQ}^{\mathrm{TM}}$ collagen becomes fluorescent upon exposure to collagenase activity. Bodipy-BSA or $\mathrm{DQ}^{\mathrm{TM}}$ collagen was incorporated into the gelatin-nylon mesh matrix layers at a concentration of 1 $\mathrm{mg} / \mathrm{ml}$, as described above.

An axiovert inverted fluorescence microscope (IM-135) with HBO-100 mercury illumination (Carl Zeiss Inc., New York, N.Y.) interfaced to a Dell 410 workstation (Round Rock, Tex.) via a Scion SG-7 video card (Vay-Tek, Fairfield, Iowa) was used. The fluorescence images were collected by an intensified, cooled charge-coupled device camera (model XC-77; Hamamatsu Photonics, Bridgewater, N.J.). Images were processed with ScionImage software and stored as TIFF files. The fluorescence of Bodipy-BSA and $\mathrm{DQ}^{\mathrm{TM}}$ collagen fluorescence was detected using a 485DF22 $\mathrm{nm}$ and 530DF30 $\mathrm{nm}$ filter combination and a 510 long-pass dichroic mirror (Omega Optical, Brattleboro, Vt.).

For image reconstruction, images from 50 to 70 optical sections were taken from a sample. To remove out-of focus fluorescence, each image was deconvoluted using MicroTome software (Vay-Tek). The 3-dimensional rendering was performed with VoxBlast software (Vay-Tek). Computations were performed on a Dell Precision Workstation. Images were printed using an Epson Stylus-Pro printer.

\section{Imaging spectrophotometry}

Fluorescence emission properties of the matrices were studied using imaging spectrophotometry. Experiments were performed as described previously (21). Briefly, a Zeiss IM135 axiovert microscope was fiber optically coupled to the input side of an Acton-150 (Acton, Mass.) imaging spectrophotometer. The exit side was connected to an intensifier, which was in turn attached to a Peltier-cooled I-MAX-512 camera (Princeton Instruments, Inc., Trenton, N.J.). The collection of spectra or images was controlled by a high-speed Princeton ST-133 interface and a Stanford Res. Systems (Sunnyvale, Calif.) DG-535 delay gate generator. This equipment was interfaced to a Dell 410 workstation running Winspec/32 version 2.3.2.5 software (Princeton Instruments, Inc.) to manage image acquisition, quantitate fluorescence levels, and analyze data. Cells were illuminated using an optical filter at 485DF22 $\mathrm{nm}$ and a 510lp dichroic mirror. 

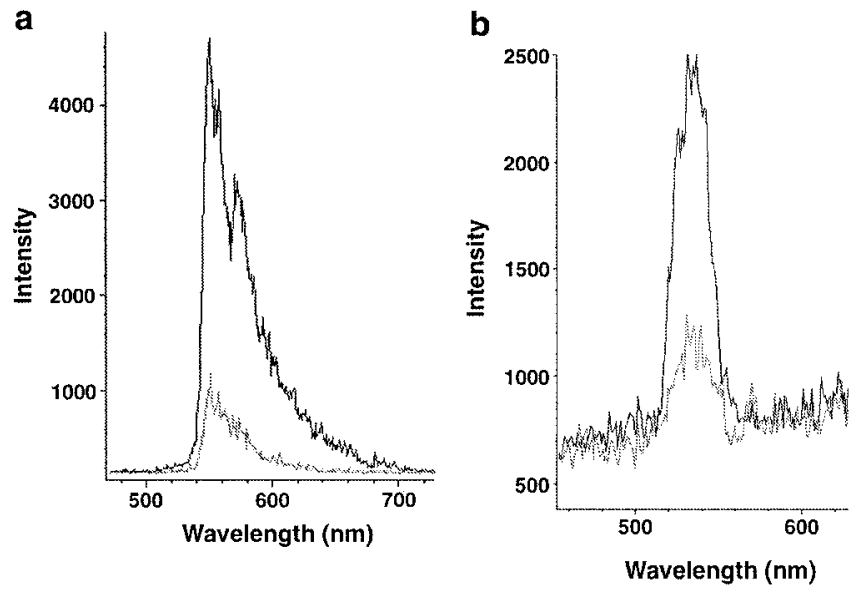

Figure 1. Fluorescence emission spectra of Bodipy-BSA and $\mathrm{DQ}^{\mathrm{TM}}$ collagen in nylon mesh-supported matrices were obtained using imaging spectroscopy. a) The fluorescence emission spectra of Bodipy-BSA are shown in the presence (solid line) and absence (dotted line) of attached tumor cells. The fluorescence emission maximum is $535 \mathrm{~nm}$. b) The fluorescence emission spectra of $\mathrm{DQ}^{\mathrm{TM}}$ collagen are shown in the presence (solid line) and absence (dotted line) of HT1080 cells. The fluorescence emission maximum is $517 \mathrm{~nm}$. For both Bodipy-BSA and $\mathrm{DQ}^{\mathrm{TM}}$ collagen, the emission intensity is greatly increased in the presence of neighboring cells.

\section{Statistical analysis}

For comparisons, Student's $t$ tests were performed. Differences were considered significant at $P<0.01$ level. Quantitative data are given as the mean \pm SD.

\section{RESULTS}

We previously described methodology to detect extracellular proteolysis in gel matrices by using Bodipy-BSA
(20). In the present study, we microscopically examine the invasiveness of HT1080 cells into 3-dimensional nylon mesh-supported matrices. To visualize proteolysis, Bodipy-BSA and fluorescein conjugated collagen $\left(\mathrm{DQ}^{\mathrm{TM}}\right.$ collagen; Molecular Probes), which become highly fluorescent on proteolysis, were used.

We first characterized the fluorescence properties of nylon mesh-supported matrices containing $1 \mathrm{mg} / \mathrm{ml}$ Bodipy-BSA or $\mathrm{DQ}^{\mathrm{TM}}$ collagen. Figure $\mathbf{1} \boldsymbol{a}$ shows the fluorescence emission spectra of Bodipy-BSA-doped matrices. The dim emission spectrum shows the inherent background fluorescence of the matrix. The companion spectrum of Fig. $1 a$ shows the emission spectrum in the presence of an adherent HT1080 cell (15 min at $37^{\circ} \mathrm{C}$ ). Clearly, the total amount of fluorescence emission is greatly increased in the presence of these cells. To more specifically image collagenase activity, we used matrices containing $\mathrm{DQ}^{\mathrm{TM}}$ collagen in the presence and absence of adherent tumor cells (Fig. 1b). Again, there was a substantial increase in fluorescence intensity, although not as great as that seen for BodipyBSA. In both cases the maximal fluorescence intensity was observed in the region of $530-550 \mathrm{~nm}$, thus indicating the fluorescein optical filters were appropriate for imaging.

We next sought to test the ability of certain inhibitors to effect the generation of pericellular fluorescence on matrices containing Bodipy-BSA or $\mathrm{DQ}^{\mathrm{TM}}$ collagen. Cells were placed on Bodipy-BSA or $\mathrm{DQ}^{\mathrm{TM}}$ collagendoped matrices, then incubated for $2 \mathrm{~h}$ at $37^{\circ} \mathrm{C}$. The number of fluorescent sites corresponding to sites of cell adherence and pericellular proteolysis were then counted. The number of fluorescent pericellular zones per high-power microscopic field for the probe-doped matrices in the presence and absence of protease inhibitors is shown in Fig. 2. Phenanthioline, a broad-
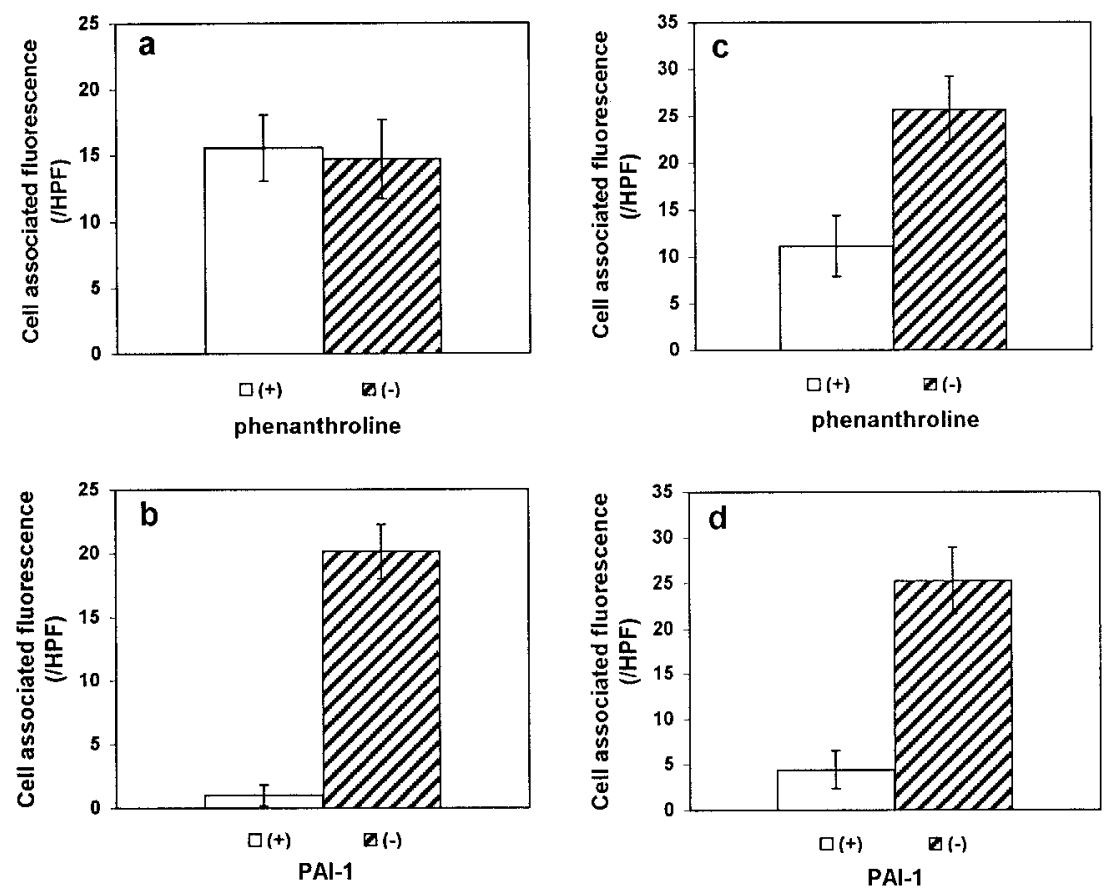

Figure 2. Effect of protease inhibitors on pericellular fluorescence of Bodipy-BSA ( $a$, $b)$ and $\mathrm{DQ}^{\mathrm{TM}}$ collagen $(c, d)$ and in nylon mesh-supported matrices. Experiments were conducted in the presence (cross-hatched bars) and absence (open bars) of 1, 10phenanthroline at $10 \mathrm{mM}(a, c)$ and PAI-1 $(0.05 \mathrm{mg} / \mathrm{ml})(b, d) .1,10$-Phenanthroline, a metalloproteinase inhibitor, substantially reduced the number of fluorescent cells per high-power microscope field (HPF) in matrices containing $\mathrm{DQ}^{\mathrm{TM}}$ collagen $(c)$, but had no effect when tested on Bodipy BSA-containing matrices $(a)$. PAI-1 substantially reduced the number of positive cells on both the Bodipy-BSA $(b)$ and $\mathrm{DQ}^{\mathrm{TM}}$ collagen $(d)$ and substrates. 
spectrum metalloproteinase inhibitor, substantially reduced proteolytic disruption of matrices containing $\mathrm{DQ}^{\mathrm{TM}}$ collagen, but not those containing Bodipy-BSA (Fig. $2 a, b$, respectively). Inasmuch as type IV collagen is cleaved by metalloproteinases (22), the ability of phenanthioline to inhibit $\mathrm{DQ}^{\mathrm{TM}}$ collagen fluorescence enhancement was expected. Similar experiments were conducted with the urokinase inhibitor PAI-1 (Fig. 2c, d). PAI-1 substantially inhibited the proteolysis of Bodipy-BSA-containing matrices and $\mathrm{DQ}^{\mathrm{TM}}$ collagen matrices. The inhibition of Bodipy-BSA cleavage by PAI-1 was expected based on prior experiments (20). The inhibitory effect of PAI-1 on collagen disruption may be partially accounted for by the fact that MMP-2 and MMP-9, which cleave type IV collagen (22), are activated by urokinase-type plasminogen activator (23). Another potential contributing factor is the ability of plasmin to degrade type IV collagen (24). Therefore, these matrices demonstrate their anticipated functional sensitivities to proteolytic disruption.

Having established the fluorescence spectroscopic properties and functional sensitivities of these matrices to protease inhibitors, we next analyzed proteolytic detection methods in 3 dimensions using the nylon mesh-supported matrices. Matrices were prepared using multiple gel layers supported by a nylon mesh skeleton, as described above. HT1080 tumor cells were seeded onto these matrices and incubated for $2 \mathrm{~h}$ at $37^{\circ} \mathrm{C}$. This incubation time allowed cells to enter and migrate through this model matrix. We found that the migratory pathways of the cells in the matrix could be visualized as a region of proteolytic destruction in the gel matrices. This simultaneously revealed the migration pathway in the gel and the nature of proteolytic action on gel during the tumor cell invasion. Figure 3 shows proteolytic trails in these extracellular gel matrices. Matrices loaded with $1 \mathrm{mg} / \mathrm{ml} \mathrm{DQ}{ }^{\mathrm{TM}}$ collagen or Bodipy-BSA are shown in Fig. $3 a, b$, respectively. The fluorescence emission of hydrolyzed $\mathrm{DQ}^{\mathrm{TM}}$ collagen or Bodipy-BSA was photographed at multiple focal planes.
The stacks of multiple images were deconvoluted by MicroTome software, then reconstructed by VoxBlast software (see Material and Methods). These images revealed tracks of proteolytic activity, i.e., tumor cell migration, through the gel matrices. In general, these 3-dimensional reconstructed images show that the proteolytic signal is most intense near cells and progressively decreases toward the point of cell entry into the matrix. The reduction in relative signal intensity and the increase in signal diameter are likely due to the diffusion of the small, cleaved fluorescent peptides from the pericellular region. Cell migration during image acquisition may also cause some blurring of the image. Figure 3 also shows selected 2-dimensional slices through the reconstructed image. We observed donutshaped regions of fluorescence (Fig. $3 b$, intermediate panel on right). Since the cell had already passed this point and was lower in the matrix, the dark area in the center likely corresponds to the wound caused in the matrix by cell migration. Later (further up the migratory trail), the fluorescence became more diffuse. Similar properties were noted with matrices containing $\mathrm{DQ}^{\mathrm{TM}}$ collagen (Fig. $3 a$ ). Thus, protein degradation in general and collagen disruption in particular are observed during tumor cell invasion of these matrices. Moreover, this provides a means to visualize the pathways followed by cells during invasion.

To illustrate how larger numbers of cells act during the invasion of these model matrices, experiments were repeated using different numbers of cells added to the top of the matrix. Figure 4 shows several independent repetitions of these experiments. Proteolysis is common in all transmigration events. The proteolysis of $\mathrm{DQ}^{\mathrm{TM}}$ collagen and Bodipy-BSA can both be observed (Fig. $4 a, b$, respectively). Most migration pathways were found to be relatively straight. The lengths of the proteolytic destruction zones were generally 150 to 200 $\mu \mathrm{m}$. In $6 \%$ gel matrices, the pathways of cell migration generally were funnel shaped due to diffusion of fluorescent peptide fragments. a

Figure 3. 3-dimensional image reconstruction of pericellular proteolysis during HT1080 transmigration of model matrices containing $\mathrm{DQ}^{\mathrm{TM}}$ collagen $(a)$ or Bodipy-BSA $(b)$. 2-Dimensional cross sections of these images are shown along the right hand sides. The ovals on the 3-dimensional images represent the areas where slices were taken as an illustration of section planes. Scale bars $=20 \mu \mathrm{m}$.

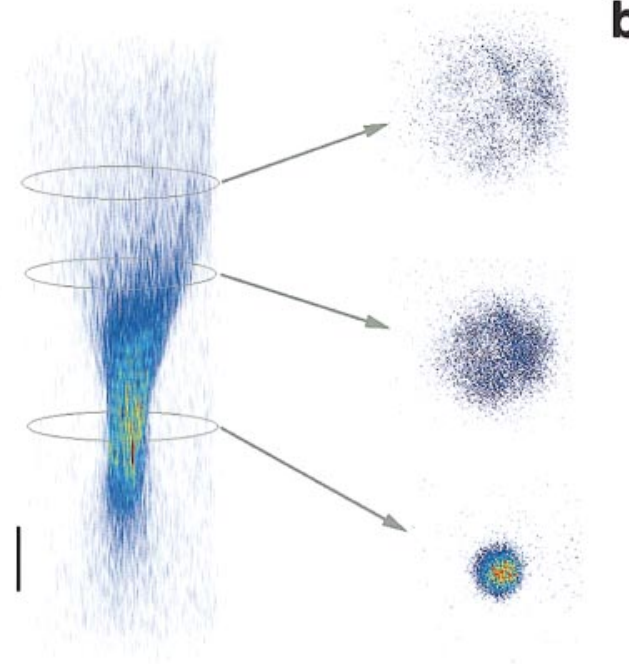

b

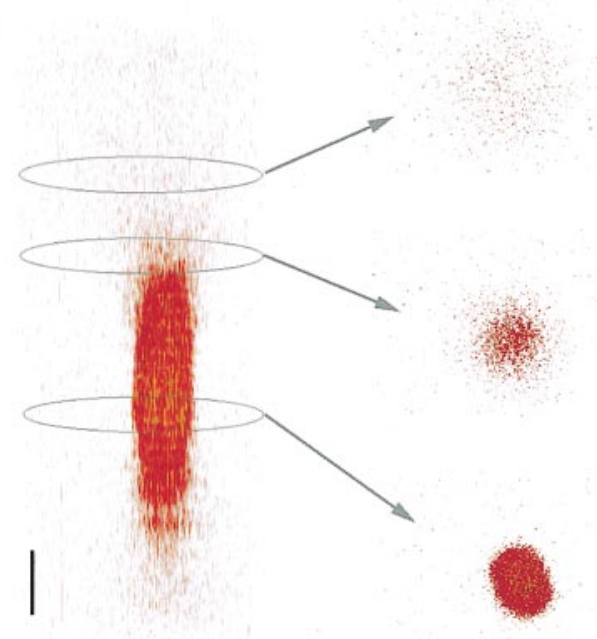




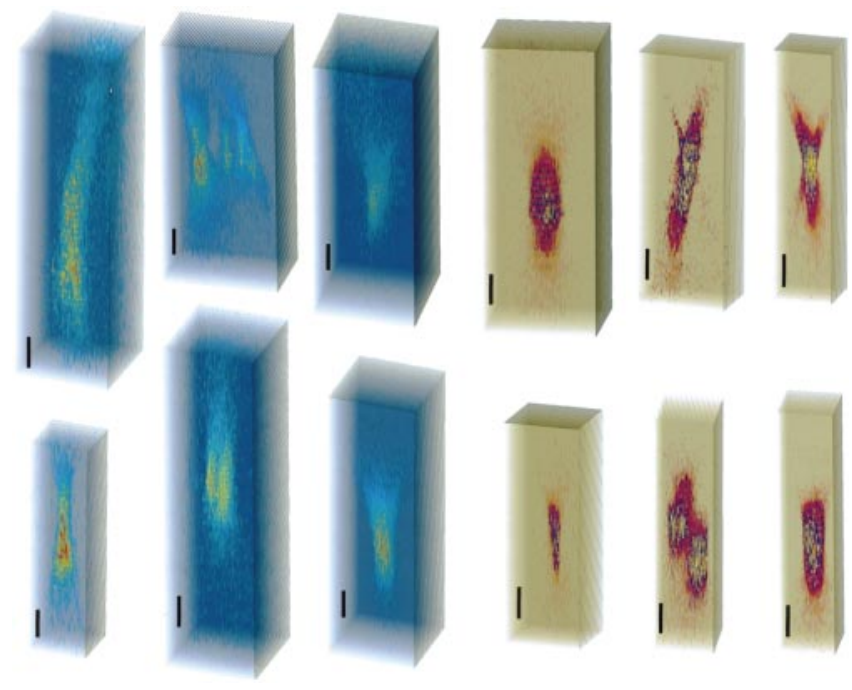

Figure 4. A gallery of representative 3-dimensional images showing HT1080 transmigration of these matrices. Images represent the fluorescence intensities of matrices detected by fluorescence of proteolytic action using $\mathrm{DQ}^{\mathrm{TM}}$ collagen $(a)$ or Bodipy-BSA $(b)$. Scale bars $=20 \mu \mathrm{m}$.

To confirm the role of pericellular proteolysis in the migration of tumor cells across this model matrix, we determined the fraction of migrated cells in the presence and absence of protease inhibitors. HT1080 cells were placed atop a matrix and incubated for $4 \mathrm{~h}$ at $37^{\circ} \mathrm{C}$ in a humidified incubator. The number of cells reaching the bottom of the matrix was then assessed. The number of cells reaching the bottom of the matrix divided by the number of input cells is shown in Fig. $\mathbf{5}$. Under the conditions used in these experiments, approximately one-half of the cells reached the bottom of the matrix. The fraction of cells reaching the bottom of the matrix was not significantly affected by the inclusion of $10 \mathrm{mM}$ 1, 10-phenanthroline (Fig. 5b). However, the fraction of HT1080 cells undergoing transmigration was dramatically reduced by the inclusion of PAI-1 (Fig. $5 a$ ). These differences could not be explained by changes in cell viability. Cell viability was assessed in the presence and absence of PAI-1 and 1, 10-phenanthroline; in all cases, cell viability was $>96 \%$. Occasionally, multiple cells migrated in the same region of the gel or as a cluster using pathways made by previously migrated tumor cells. In some cases, cells would stop for short periods in the gel, resulting in inhomogeneities in fluorescence intensity. Nonetheless, cell migration through the gel was characterized by linear pathways rich in proteolysis.

Cell-cell cooperation may participate in the invasive program of tumor cells under certain conditions (2527). Specifically, uPAR-positive tumor or stromal cells may participate in the invasiveness of uPAR-negative tumor cells. We therefore used our in vitro 3-dimensional invasion imaging method with a heterogeneous cell population. We tested the hypothesis that UPARexpressing cells affect the invasive behavior of uPARnegative cells. To perform this experiment, we used the T-47D cell line, which is less invasive than the HT1080 cell line, and a derivative of the T-47D cell line, T-47D A2-1, which has been transfected with a uPAR-containing vector. The T-47D A2-1 transfectant expresses UPAR and demonstrates greatly enhanced proteolytic activity in comparison to the parental T-47D line (see below). The use of the T-47D and T-47D A2-1 cell lines avoids the introduction of other potentially confounding variables with cells from different sources. The T-47D cells were labeled with the fluorescent probe DiI, as described in Materials and Methods. A single cell suspension of $2 \times 10^{4} \mathrm{~T}-47 \mathrm{D}$ A2-1 cells and $2 \times 10^{4}$ DiI-labeled T-47D cells was prepared. These cells were suspended in $50 \mu \mathrm{l}$ of HBSS containing $6 \%$ gelatin and layered atop a gel matrix containing $\mathrm{DQ}^{\mathrm{TM}}$ collagen. After $30 \mathrm{~min}$ at $37^{\circ} \mathrm{C}$, samples were placed on a $37^{\circ} \mathrm{C}$ microscope stage. Forty to 50 image planes were collected for the DiI probe (T-47D localization, red) and another precisely matched image stack was collected at a separate wavelength for $\mathrm{DQ}^{\mathrm{TM}}$ collagen (proteolytic action, blue). $\mathrm{DQ}^{\mathrm{TM}}$ collagen fluorescence emission is restricted to the location of, or trail of, T-47D A2-1 cells. Although sensitive imaging techniques have revealed some pericellular proteolytic activity near T-47D cells, the intensity of this fluorescence is too low to be detected in these experiments. Figure 6 shows representative examples of mixed tumor cell invasion experiments. Figure $6 \mathrm{~A}$ shows an example of a T-47D cell following a path produced by the T-47D A2-1 cell. The DiI emission profile in this figure is significantly larger than the size of a cell. Since these cells are migrating and time is required to capture an image and move the stage to the next plane, some blurring of the images is expected. Figure $6 B$ shows results similar to those of Fig. $6 A$ except that the T-47D cell is migrating at an
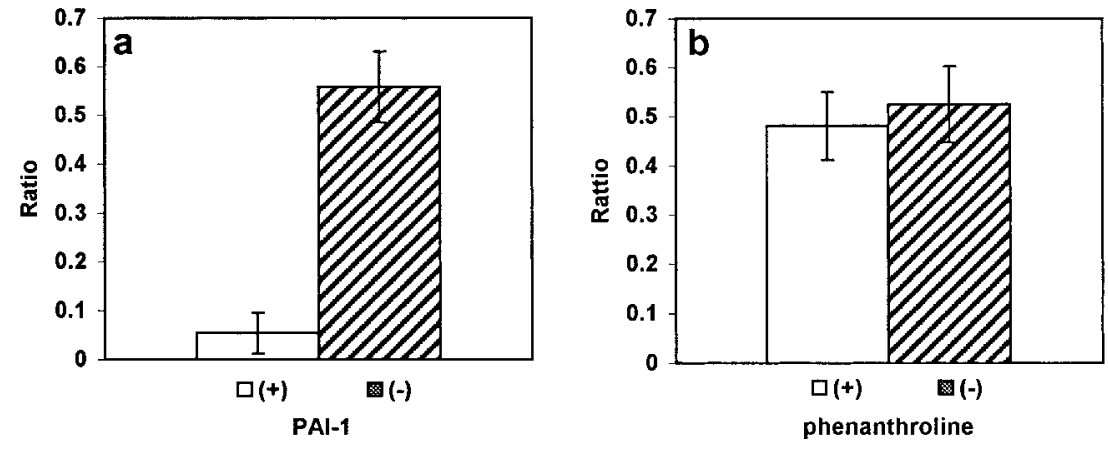

Figure 5. Effect of protease inhibitors on migration across the nylon mesh-supported gel matrices. The number of cells reaching the bottom surface of the matrix after a $4 \mathrm{~h}$ incubation at $37^{\circ} \mathrm{C}$ was divided by the number of cells added to the top layer to determine the fraction of cells that migrated across the matrix. Experiments were performed in the presence (open bars) and absence (striped bars) of inhibitors. Although PAI-1 was found to substantially inhibit cell appearance at the bottom surface $(a), 1,10$-phenanthroline was found to have no effect $(b)$. 

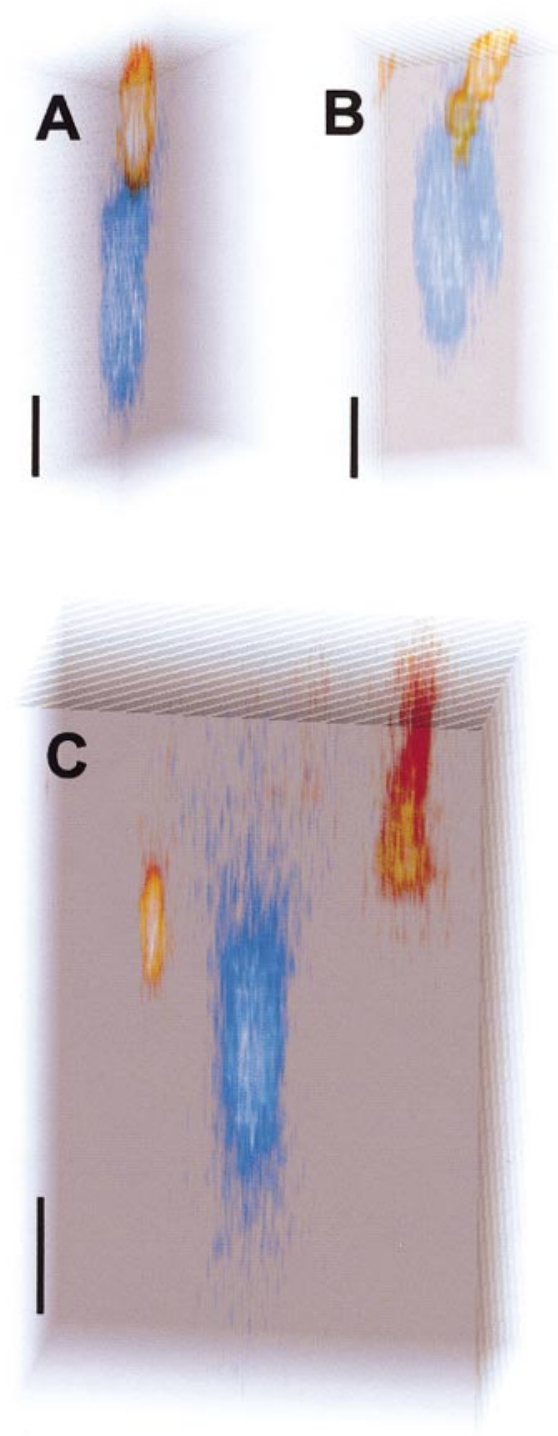

Figure 6. 3-Dimensional image reconstruction of tumor cell migration through model matrices containing $\mathrm{DQ}^{\mathrm{TM}}$ collagen. Experiments were performed using T-47D cells that do not express UPAR and T-47D A2-1 cells that express UPAR. Equivalent numbers of cells were mixed and added to the top of supported gel matrices. T-47D cells were labeled with DiI to reveal their location in the gel (red in micrographs). The locations proteolytic activity are shown in blue. Collagen disruption likely mediated by uPAR-mediated enhancement of UPA activity and UPA-mediated activation of MMPs (17) and plasmin activation (24). A) A T-47D cell is following a T-47D A2-1 cell across the matrix. B) A T-47D cell migrates at an angle to intersect the pathway formed by a T-47D A2-1 cell. C) Two T-47D cells that are crossing the matrix without directly after the T-47D A2-1 cell. (Quantitative data are shown in Fig. 7.) Scale bars $=20 \mu \mathrm{m}$.

angle toward the pathway created by the T-47D A2-1 cell. In other examples (Fig. 6C), the pathways followed by T-47D cells were not colinear with T-47D A2-1 cells. Quantitative analyses of cell migration are shown in Fig. 7. This figure shows the migration ratio of T-47D and T-47D A2-1 cells in the presence and absence of the other cell type. As expected, migration of the uPARexpressing T-47D 2A-1 cell line was substantially greater than the wild-type uPAR-negative T-47D cells when examined separately. However, when the mixed cell experiment was performed, the migration of the T-47D 2A-1 cells was not affected whereas the migration of the DiI-labeled T-47D cells became indistinguishable from their uPAR-expressing counterparts. One potential mechanism contributing to this is matrix disruption provided by the uPAR-positive cells (Fig. $6 A$ ).

\section{DISCUSSION}

The primary cause of death from cancer is cell invasion of neighboring tissues and formation of distant metastases. Pericellular proteolysis is a key step required for the invasion of tumor cells. Pericellular proteolytic activity is required for disruption of basement membranes and interstitial tissues and the penetration of cell layers. Two families of enzymes thought to participate in the pericellular proteolysis associated with the invasive program of tumor cells are plasminogen activators and matrix metalloproteinases $(2-9,19)$. However, the relative importance of these two types of enzymatic activities apparently varies among tumor cell types $(2-9,19)$. The present study focused on pericellular proteolysis-dependent events occurring during tumor cell invasion of a model matrix.

The present study is of considerable interest from both technological and physiological viewpoints. Using an open mesh nylon grid for support, multiple gel layers were deposited on the mesh. By adding a small amount of gel to the mesh at a time, multiple layers could be built up into a thicker matrix-like assembling plywood. The open mesh also affords the ability to use both transmitted light and epifluorescence microscopy to image events in a sample. This is a substantial

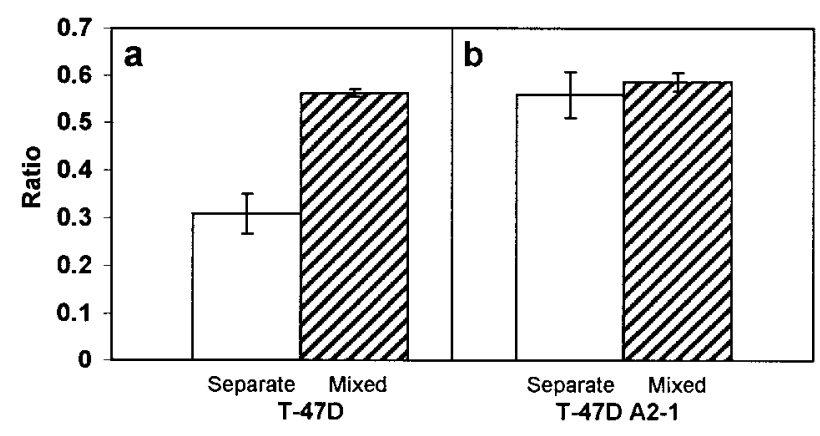

Figure 7. Quantitative analysis of the effect of uPAR-positive T-47D A2-1 cells on the invasive ability of uPAR-negative T-47D cells. Experiments were performed as described in Fig. 6 and the text. The number of cells reaching the bottom surface of the matrix after a $4 \mathrm{~h}$ incubation at $37^{\circ} \mathrm{C}$ was divided by the number of cells added to the top layer to determine the fraction of cells that migrated across the matrix. The ability of T-47D cells to traverse the matrix was measured in the absence (open bars) and presence (striped bars) of T-47D A2-1 cells $(a)$. The ability of T-47D cells to cross the matrix was enhanced by the presence uPAR-expressing T-47D A2-1 cells. However, T-47D cells had no influence on the ability of T-47D A2-1 cells to migrate across the gel (b). 
advantage over invasion assays that rely on cell migration through artificial pores. Another advantage of these nylon mesh-supported matrices is that most of the surface area is available for transmigration to the bottom of the matrix. In contrast, only a small fraction of a filter's surface area is available in the form of pores to permit migration to the bottom of the matrix. In many experiments using the filter assay, cells must 'squeeze' through the pores in the plastic filters, an action that has no clear counterpart in cell physiology. It is not clear whether the pore assays are measuring the kinetics of transmigration or the kinetics of finding an available pore. Moreover, these gel matrices can also be tailored to address specific experimental hypotheses. In this study, for example, we included substrates (Bodipy$\mathrm{BSA}$ and $\mathrm{DQ}^{\mathrm{TM}}$ collagen) within the matrix that become fluorescent upon proteolytic cleavage, thus revealing the location of functioning enzymes. When these assays were conducted for extended periods of time, the pathways followed by cells during this model transmigration process could be imaged. Our approach is particularly valuable in studying transmigration since bright-field microscopy is unrevealing under these circumstances because the refractive index of cells matches that of the extracellular matrix. Thus, we have developed the technology suitable for addressing several critical issues surrounding the invasive ability of cancer cells.

Proteolysis of the extracellular matrix is believed to be necessary for the invasive and migratory capacity of cells. The proteinases thought to be largely responsible for the degradation of the extracellular matrix are the matrix metalloproteinases and plasminogen activators $(2-9,19)$. The detection of these activities in situ relies on the generation of fluorescent peptides after protein cleavage. To confirm the relevance of the Bodipy-BSA and $\mathrm{DQ}^{\mathrm{TM}}$ collagen probes, we tested their ability to disrupt matrices in the presence of the inhibitors PAI-1 and 1, 10-phenanthroline. PAI-1 and 1, 10-phenanthroline substantially inhibited the release of fluorescent peptides from Bodipy-BSA and $\mathrm{DQ}^{\mathrm{TM}}$ collagen, respectively. Thus, these probes are appropriate for the detection of these enzymatic activities. The present study demonstrates proteolysis and collagen disruption during cell migration across these model matrices. Although much work has suggested a role of collagen disruption in cell migration through complex matrices, our work provides direct evidence for the cell-mediated disruption of collagen during tumor cell invasion.

Several previous studies have traced the pathways of leukocyte movement in 3-dimensional gels $(28,29)$. These studies are very time consuming because they necessarily followed just one cell over a long period of time. By detecting the enzymatic activities associated with transmigration, we were able to image the migratory pathways of many cells. By collecting image stacks from different focal planes in a gel, we can collect data from multiple cells from a single experiment.

We also confirmed the relevance of particular enzyme activities imaged in the present study with in vitro migration in these model matrices. PAI-1 and 1, 10phenanthroline were incorporated into the matrices at high concentrations before their solidification. PAI-1, but not 1, 10-phenanthroline, was found to substantially inhibit the ability of tumor cells to cross the matrix. This is consistent with earlier studies indicating that urokinase-type plasminogen activator plays an important role in tumor cell invasiveness (e.g., ref 30). Since there is some variability in the relative importance of urokinase and matrix metalloproteinases among different types of cancer cells $(2-9,19)$, this result should not be interpreted to mean that metalloproteinases are unimportant to tumor cell invasion in general.

Previous studies have shown that uPAR-positive cells express an invasive phenotype (e.g., refs 8-11, 30). uPAR-negative cells can also be invasive. One mechanism that may account for the invasiveness of UPARnegative cells is cross-talk among uPAR-positive and uPAR-negative cell types. For example, uPAR-negative tumor cells may collaborate with uPAR-positive stromal cells during invasion (e.g., ref 25). Having developed the technology to observe proteolytic trails in matrices, we examined the ability of uPAR-positive cells to facilitate the invasive behavior of uPAR-negative cells. To perform this test, we used uPAR-negative T-47D cells and T-47D transfectants expressing uPAR. We found that the presence of uPAR-positive cells enhanced the ability of uPAR-negative cells to migrate across the matrix. The microscopy studies of Fig. 6 suggest that the ability of uPAR-negative cells to follow uPAR-positive cells across a matrix can partially account for this. Thus, matrix disruption by uPAR-positive cells could facilitate a 'follow the leader' type mechanism during matrix invasion by uPAR-negative cells.

The 3-dimensional model of cell transmigration and extracellular proteolysis described above should be generally applicable in studies of invasion and transmigration. For example, the extracellular matrix components could be tailored to reflect specific microenvironments. Other cell types could be added to the matrix itself during formation and to the top or bottom of the nylon mesh-supported matrix after formation. Moreover, it should be possible to monitor several biochemical reactions in addition to the proteolytic reactions noted above. For example, it is known that tumor cells can produce superoxide anions (31). Such oxidants could be detected in this tissue-like environment as well. Thus, we expect that this approach will become a valuable tool in cancer biology.

Supported by National Institutes of Health grants EY09441 (V.M.E.), AI27409 (H.R.P.), EY007003 (V.M.E.) and by Research to Prevent Blindness-Olga Keith Weiss Award (V.M.E.).

\section{REFERENCES}

1. Erkell, L. J., and Schirrmacher, V. (1988) Quantitative in vitro assay for tumor cell invasion through extracellular matrix or into protein gels. Cancer Res. 48, 6933-6937 
2. Montgomery, A. M. P., De Clerck, Y. A., Langley, K. E., Reisfeld, R. A., and Mueller, B. M. (1993) Melanoma-mediated dissolution of extracellular matrix: contribution of urokinase-dependent and metalloproteinase-dependent proteolytic pathway. Cancer Res. 53, 693-700

3. Monsky, W. L., Lin, C. Y., Aoyama, A., Kelly, T., Akiyama, S. K., Mueller, S. C., and Chen, W. T. (1994) A potential marker protease of invasiveness, seprase, is localized on invadopodia of human malignant melanoma cells. Cancer Res. 54, 5702-5710

4. McCawley, L. J., and Matrisian, L. M. (2000) Matrix metalloproteinases: multifunctional contributors to tumor progression. Mol. Med. Today 4, 149-156

5. Curran, S., and Murray, G. I. (1999) Matrix metalloproteinases in tumour invasion and metastasis. J. Pathol. 189, 300-308

6. Ellerbrock, S. M., and Stack, M. S. (1999) Membrane associated matrix metalloproteinases in metastasis. Bioessays 21, 940-949

7. Murphy, G., and Gavrilovic, J. (1999) Proteolysis and cell migration: creating a path? Curr. Opin. Cell Biol. 11, 614-621

8. Dano, K., Romer, J., Nielsen, B. S., Bjorn, S., Pyke, C., Rygaard, J., and Lund, L. R. (1999) Cancer invasion and tissue remodeling-cooperation of protease systems and cell types. APMIS 107, $120-127$

9. Reich, R., Thompson, E. W., Iwamoto, Y., Martin, G. R., Deason, J. R., Fuller, G. C., and Miskin, R. (1988) Effects of inhibitors of plasminogen activator, serine proteinases, and collagenases IV on the invasion of basement membranes by metastatic cells. Cancer Res. 48, 3307-3312

10. Hart, I. R., and Fidler, I. J. (1978) An in vitro quantitative assay for tumor cell invasion. Cancer Res. 38, 3218-3224

11. Poste, G., Doll, J., Hart, I. R., and Fidler, I. J. (1980) In vitro selection of murine B 16 melanoma variants with enhanced tissue-invasive properties. Cancer Res. 40, 1636-1644

12. Mignatti, P., Robbins, E., and Rifkin, D. B. (1986) Tumor invasion through the human amniotic membrane: requirement for a proteinase cascade. Cell 47, 487-498

13. Liotta, L. A., Lee, W. C., and Morakis, D. J. (1980) New method for preparing large surfaces of intact basement membrane for tumor invasion studies. Cancer Lett. 11, 141-147

14. Ossowski, L., and Reich, E. (1980) Experimental model for quantitative study of metastasis. Cancer Res. 40, 2300-2309

15. Starkey, J. R., Hosick, H. L., Stanford, D. R., and Liggitt, H. D. (1984) Interaction of metastatic tumor cells with bovine lens. Cancer Res. 44, 1585-1594

16. Albini, A., Iwamoto, Y., Kleinman, H. K., Martin, G. R., Aaronson, S. A., Kozlowski, J. M., and McEwan, R. N. (1987) A rapid in vitro assay for quantitating the invasive potential of tumor cells. Cancer Res. 47, 3239-3245

17. Xue, W., Mizukami, I., Todd, I. I. I., R. T., and Petty, H. R. (1997) Urokinase-type plasminogen activator receptors associate with $\beta 1$ and $\beta 3$ integrins of fibrosarcoma cells: dependence on extracellular matrix components. Cancer Res. 57, 1682-1689

18. Kuriyama, S., Yamazaki, M., Mitoro, A., Tsujimoto, T., Kikukawa, M., Okuda, H., Tsujinoue, H., Nakatani, T., Yoshiji, H., Toyokawa, Y., Nagao, S., and Fukui, H. (1998) Analysis of intrahepatic invasion of hepatocellular carcinoma using fluorescent dye-labeled cells in mice. Anticancer Res. 18, 4181-4188

19. Garbett, E. A., Reed, M. W. R., and Brown, N. J. (1999) Proteolysis in human breast and colorectal cancer. Br. J. Cancer 81, 287-293

20. Kindzelskii, A. L., Zhou, M. J., Haugland, R. P., Boxer, L. A., and Petty, H. R. (1998) Oscillatory pericellular proteolysis and oxidant deposition during neutrophil locomotion. Biophys. J. 74, $90-97$

21. Kindzelskii, A. L., Yang, Z., Nabel, G. J., Todd, I. I. I., R. F., and Petty, H. R. (2000) Ebola virus secretory glycoprotein (sGP) disrupts Fc $\gamma$ RIIIb to CR3 proximity on neutrophils. J. Immunol. 164, 953-958

22. Baramova, E., and Foidart, J. M. (1995) Matrix metalloproteinases family. Cell Biol. Int. 19, 239-242

23. Goldberg, G. I., Frisch, S. M., He, C., Wilhelm, S. M., Reich, R., and Collier, I. E. (1990) Secreted proteases. Regulation of their activity and their possible role in metastasis. Ann. N.Y. Acad. Sci. $\mathbf{5 8 0}, 375-384$

24. Mackay, A. R., Corbitt, R. H., Hartzler, J. L., and Thorgeirsson, U. P. (1990) Basement membrane type IV collagen degradation: evidence for the involvement of a proteolytic cascade independent of metalloproteinases. Cancer Res. 50, 5997-6001

25. Romer, J., Pyke, C., Lund, L. R., Eriksen, J., Kristensen, P., Ronne, E., Hansen, H. G., Dano, K., and Brunner, N. (1994) Expression of $\mathrm{uPA}$ and its receptor by both neoplastic and stromal cells during xenograft invasion. Int. J. Cancer 57, 553560

26. Kennedy, S., Duffy, M. J., Duggan, C., Barnes, C., Rafferty, R. and Kramer, M. D. (1998) Semi-quantitation of urokinase plasminogen activator and its receptor in breast carcinomas by immunocytochemistry. Br. J. Cancer 77, 1638-1641

27. DeClerck, Y. A., and Laug, W. E. (1996) Cooperation between matrix metalloproteinases and the plasminogen activator-plasmin system in tumor progression. Enzyme Protein 49, 72-84

28. Haddox, J. L., Pfister, R. R., and Sommers, C. I. (1991) A visual assay for quantitating neutrophil chemotaxis in a collagen gel matrix. A novel chemotactic chamber. J. Immunol. Meth. 141, 41-52

29. Parkhurst, M. R., and Saltzman, W. M. (1992) Quantification of human neutrophil motility in three-dimensional collagen gels. Effect of collagen concentration. Biophys. J. 61, 306-315

30. Towle, M. J., Lee, A., Maduakor, E. C., Schwartz, C. E., Bridges, A. J., and Littlefield, B. A. (1993) Inhibition by 4-substituted benzo [b] thiophene-2-carboxamidines: an important new class of selective synthetic urokinase inhibitor. Cancer Res. 53, 25532559

31. Szatrowski, T. P., and Nathan, C. F. (1991) Production of hydrogen peroxide by human tumor cells. Cancer Res. 51, $794-798$

Received for publication July 16, 2000 Revised for publication October 3, 2000. 